\title{
Sex determination and differentiation in mammals: hints from nature
}

\author{
(Abstract) \\ P. E. Polani \\ M.D., F.R.C.P., F.R.S.
}

Paediatric Research Unit, Guy's Hospital Medical School, London SE1 9RT

THERE are a number of experiments that nature has carried out, in man and other animals, that have helped us considerably in achieving the present understanding of sex determination and differentiation. Some of the key experiments are concerned with:

(1) The origin of the germ cells from the wall of the extraembryonic gut, to an understanding of which the $W$ mutants in the mouse have contributed well.

(2) The maintenance of the germ cells which in mammals demands not only the 'right' gonadal ambient but also its correct chromosomal make-up and correspondence with that of the germ cells (see below).

(3) The key role of the $Y$ chromosome in sex determination (namely gonad formation). This was established from the discovery of the sex chromosome anomalies in man (and the mouse), the XO $(45, X)$ and $X X Y(47, X X Y)$ complements. Other 'experiments', in man, with chromosome deletions, would suggest that the sex-determining factor(s) of the $Y$ is on the short arm of this chromosome, now known to be that which associates at meiosis with the $\mathrm{X}$ chromosome. Studies, in embryos of the very frequent and very lethal $45, X$ condition, have uncovered the fact that an ovary develops with a single $\mathrm{X}$ chromosome (i.e. does not need the second $\mathrm{X})$ which thus is not a sex determining chromosome, as far as we know, but that its 'inert variant' (the X-chromatin, or Barr-body, forming X) is essential for ovarian upkeep and function and thus for continued oögenesis. Yet other experiments (the XX male in man, the goat and the mouse, and the XO male mouse) suggest that 'switch' genes for testicular development may exist on the autosomes and be capable of working without a Y, i.e. they may take over its function in unison with two Xs, or (not surprisingly) better still with a single $X$. But this arrangement is not fully satisfactory as far as the production of competent mature germ cells is concerned.

There is a variety of points concerning sex differentiation which should be stressed:

(i) The importance for Wolffian duct development of the selective responsiveness of receptors in target organ cells to the quantity of male hormone produced by the fetal testis. It appears that when the receptor proteins are 'mutant' and non-inducible (testicular feminization in man and the mouse, for example), the Wolffian derivatives are not enhanced. Here the action of the hormone would be intracanalicular.

(ii) The significance of the action of the same hormone, in male quantities, on the receptors of cells of the external genitals causes external masculinization. Here the action of the hormone could be via the blood stream.

(iii) The importance of an apparently non-steroid hormone for Müllerian duct involution in the male. Is it produced by the Sertoli cells? Are there known mutations?

There are many obscurities left and gaps to be filled by these and other points which are to be gleaned by accurate observation. An important area for study concerns the 'sex of the brain'.

\section{References}

Polani, P.E. (1970) Hormonal and clinical aspects of hermaphroditism and the testicular feminisation syndrome in man. Philosophical Transactions of the Royal Society, London (Series B), 259, 187.

Polani, P.E. (1970) Chromosome phenotypes-sex chromosomes. In: Congenital Malformations (Ed. by Clarke, Fraser and McKusick), p. 233. Proceedings of the 3rd International Conference on Congenital Malformations (7-13 Sept.). Excerpta Medica International Congress Series No. 204.

OUNSTED, C. \& TAYLOR, D.C. (Editors) (1972) Errors of sex determination and sex chromosome anomalies. In: Gender Differences: Their Ontogeny and Significance, chapter 2, p. 13. Churchill Livingstone, Edinburgh. 